\section{Gategory}

\section{Synthesis of}

Heterocycles

\section{Key words}

spirocycles

oxindoles

Ullmann coupling

Claisen

rearrangement
H. MIYAMOTO, T. HIRANO, Y. OKAWA, A. NAKAZAKI, * S. KOBAYASHI* (TOKYO UNIVERSITY OF SCIENCE, CHIBA, JAPAN)

Stereoselective Synthesis of Spirocyclic Oxindoles Based on a One-Pot Ullmann Coupling/Claisen Rearrangement and its Application to the Synthesis of a Hexahydropyrrolo[2,3- $b$ ]indole Alkaloid Tetrahedron 2013, 69, 9481-9493.

\title{
Construction of Spirocyclic Oxindoles for Indole Alkaloid Synthesis
}

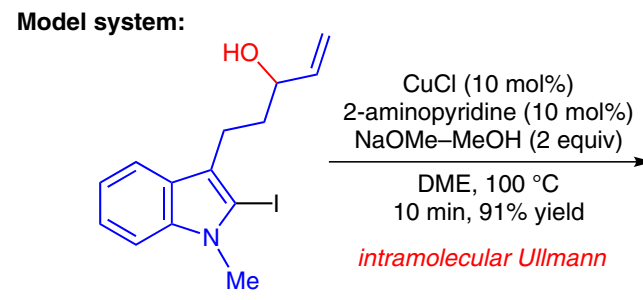

Application to total synthesis:

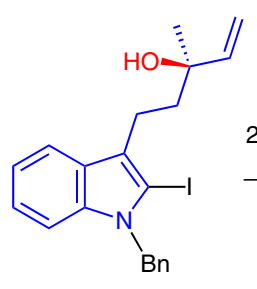

(R) $97 \%$ ee

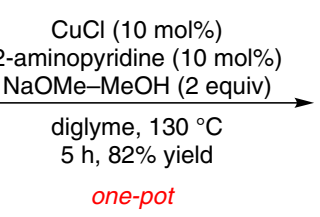

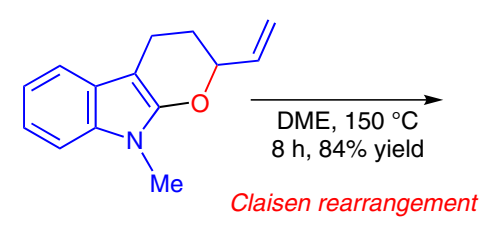
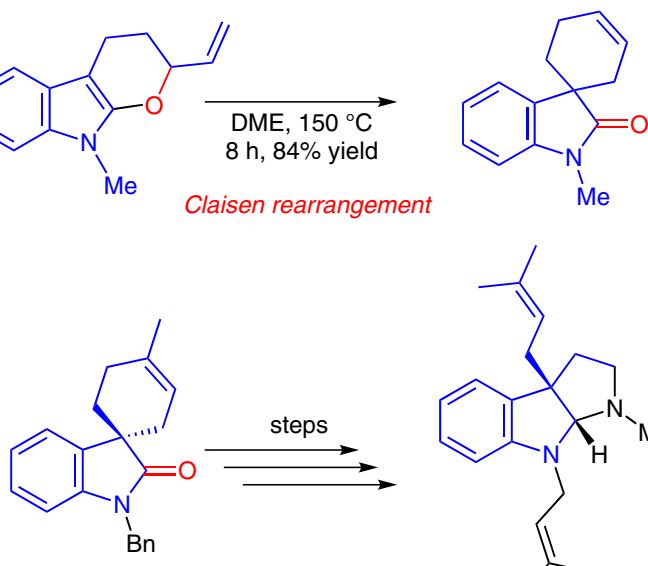

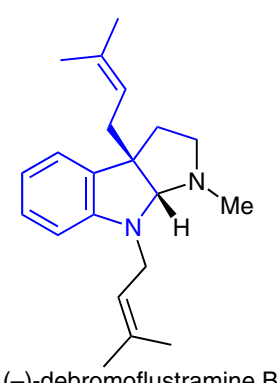

(-)-debromoflustramine B
(S) $95 \%$ ee
Significance: Oxindoles bearing a quaternary stereogenic center at C3 represent attractive synthetic targets due to both their biological activity and their utility as synthetic intermediates. Kobayashi and co-workers have previously reported a stereoselective Claisen rearrangement of bicyclic dihydropyrans to provide multifunctionalized spiro[4.5]decanes (see Review below). The current study extends this methodology to the rearrangement of pyranoindoles, which are accessed from readily synthesized 2-haloindoles through an intramolecular Ullmann condensation (IUC), to yield spirocyclic oxindoles in a stereoselective manner. Oxidative cleavage of the olefin moiety of the products leads to stereochemically defined oxindoles, which can be readily elaborated into members of the hexahydropyrrolo[2,3$b]$ indole family of alkaloids, as demonstrated by the synthesis of (-)-debromoflustramine B.

Review: A. Nakazakia, S. Kobayashi Synlett 2012 23, 1427-1445.

SYNFACTS Contributors: Victor Snieckus, Paul Richardson (Pfizer) Synfacts 2014, 10(1), 0026 Published online: 13.12.2013 Dol: 10.1055/s-0033-1340424; Reg-No.: V15513SF
Comment: Optimization studies demonstrated that the IUC proceeded best under modified Hauptman coupling conditions ( $\mathrm{CuCl}$, 2-aminopyridine, $\mathrm{NaOMe}$ ). The Claisen rearrangement occurred simply by heating the intermediate pyranoindoles. Due to issues with the stability of the intermediates, a one-pot sequence was developed in which, on completion of the IUC, the temperature was raised to effect the rearrangement. Indoles incorporating trans substituents on the allylic alcohol afforded the oxindole as single diastereomers (NOE, X-ray analyses), the stereochemistry of which indicated that the rearrangement proceeds through a boat-like transition state. The cis isomers did not give the desired products, and attempts to form furanoindoles also failed. A range of $\mathrm{N}$-indole protecting groups were tolerated. A remarkable rate enhancement was observed running the reaction in glyme solvents, which avoided the use of a sealed tube. Subjecting enantiopure secondary alcohols to the reaction led to a slight erosion in enantiomeric excess (10-15\% ee), whereas the ee of chiral tertiary alcohols was maintained. 